\title{
A medicação antirretroviral como expressão do cuidado com a vida: adesão, esperança e de longevidade
}

\author{
Antiretroviral medication as an expression of care for life: adherence, hope and longevity \\ La medicación antirretroviral como expresión de cuidado para la vida: adherencia, esperanza y lon- \\ gevidad
}

\section{Marcia Pereira Gomes $^{1 *}$, Diogo Jacintho Barbosa ${ }^{2}$, Fabiana Barbosa Assumpção de Souza ${ }^{3}$, Antônio Marcos Tosoli Gomes ${ }^{4}$, André Luís Brugger e Silva ${ }^{5}$, Girlene Alves da Silva ${ }^{6}$}

Como citar esse artigo. Gomes, MP; Barbosa, DJ; de Souza, FBA; Gomes, AMT; Silva, ALB; da Silva, GA. A medicação antirretroviral como expressão do cuidado com a vida: adesão, esperança e de longevidade. Revista Pró-UniverSUS. 2020 Jul./Dez.; 11 (2): $164-167$

\section{Resumo}

Objetivos: descrever e discutir o papel da medicação antirretroviral no cotidiano das pessoas vivendo com HIV. Método: qualitativo, descritivo. Entrevistas com 49 pessoas que vivem com HIV. Técnica de análise de conteúdo lexical, com auxílio do software Iramuteq 0.7 alpha 2. Resultados: a medicação antirretroviral é vista pelos participantes do estudo como uma segunda chance para a vida, onde a adesão a terapia medicamentosa oferece possibilidades de uma vida boa, com qualidade e longevidade. Ancorados na esperança que ressignifica o olhar sobre a síndrome, para além das limitações da mesma percebendo a oportunização de novos caminhos principalmente pela medicalização. Conclusão: Os resultados mostram que os indivíduos entendem o tratamento como uma segunda chance para a vida, não é a cura mas permite uma maior expectativa de vida e melhor qualidade de vida, mas que para tal precisam participar ativamente da gestão do seu autocuidado, aderindo a terapia medicamentosa.

Palavras-chave: Adesão; PVHIV; TARV.

\begin{abstract}
Objectives: To describe and discuss the role of antiretroviral medication in the daily lives of people living with HIV. Method: qualitative, descriptive. Interviews with 49 people living with HIV. Lexical content analysis technique, with the aid of Iramuteq 0.7 alpha 2 software. Results: Antiretroviral medication is seen by study participants as a second chance for life, where adherence to drug therapy offers possibilities for a good life, quality and longevity. Anchored in the hope that reframes the look on the syndrome, beyond its limitations realizing the opportunity of new ways mainly by medicalization. Conclusion: The results show that individuals understand treatment as a second chance for life, it is not a cure, but it allows longer life expectancy and better quality of life, but they need to actively participate in the management of their self-care, adhering to it. drug therapy.

Keywords: Accession; ART; PVHIV.
\end{abstract}

\section{Resumen}

Objetivos: describir y discutir el papel de la medicación antirretroviral en la vida diaria de las personas que viven con el VIH. Método: cualitativo, descriptivo. Entrevistas con 49 personas que viven con el VIH. Técnica de análisis de contenido léxico, con la ayuda del software Iramuteq 0.7 alpha 2. Resultados: los participantes del estudio consideran que la medicación antirretroviral es una segunda oportunidad para la vida, donde la adherencia a la terapia farmacológica ofrece posibilidades para una buena vida, con calidad y longevidad. Anclado en la esperanza que le da un nuevo significado a la mirada sobre el síndrome, más allá de las limitaciones del mismo, aprovechando la oportunidad de nuevos caminos principalmente a través de la medicalización. Conclusión: Los resultados muestran que las personas entienden el tratamiento como una segunda oportunidad de vida, no es una cura, pero permite una mayor esperanza de vida y una mejor calidad de vida, pero para eso necesitan participar activamente en el manejo de su autocuidado, adhiriéndose Terapia farmacológica.

Palabras clave: Membresía; ARTE; PVVS.

Afiliação dos autores:

${ }^{1}$ Enfermeira. Mestre em Enfermagem pelo Programa Pós- Graduação em Enfermagem da Universidade Federal do Estado do Rio de Janeiro (UNIRIO). RJ, Brasil. ORCID: https:// orcid.org/0000-0003-3135-2570

${ }^{2}$ Professor Substituto da Universidade Federal do Rio de Janeiro-UFRJ, Doutorando em Enfermagem na Faculdade de Enfermagem da UERJ. RJ. Brasil. ORCID: https://orcid. org/0000-0001-6171-0768

${ }^{3}$ Pós Doutora em Aids. Professora da EEAP/UNIRIO. RJ, Brasil. ORCID: https://orcid.org/0000-0001-8098-5417

${ }^{4}$ Doutor em Enfermagem. Professor e Coordenador Adjunto do Programa de Pós-Graduação em Enfermagem da UERJ. Pesquisador do grupo de pesquisa Promoção da Saúde e Práticas de Cuidado de Enfermagem e de Saúde dos Grupos Populacionais. RJ, Brasil. ORCID: https://orcid.org/0000-0003-4235-9647

${ }^{5}$ Enfermeiro. Mestre em Enfermagem pelo Programa de Pós-Graduação em Enfermagem da Universidade Federal do Estado do Rio de Janeiro (UNIRIO). Juiz de fora, Minas Gerais -Brasil. ORCID: https://orcid.org/0000-0002-1514-6980

${ }^{6}$ Doutora em Enfermagem. Professora Associada da faculdade de enfermagem da UFJF. Juiz de fora, Minas Gerais -Brasil.ORCID: https://orcid.org/0000-0002-8758-1156

* Email de correspondencia: mpsemog@gmail.com 


\section{Introdução}

Em 2017 cerca de 36,9 milhões de pessoas viviam com HIV em todo o mundo sendo 1,8 milhão na América Latina. No Brasil foram notificados no Sistema Nacional de Notificação (Sinan) 42.420 casos de infecção pelo HIV. Demonstrando a importância e o impacto da infecção pelo HIV na saúde publica. No mundo 21,7 milhões de pessoas vivendo com HIV (PVHIV) tiveram acesso à terapia antirretroviral e na América Latina 1,1 milhão ${ }^{1,2}$. O Brasil foi o primeiro país em desenvolvimento a garantir acesso universal e gratuito aos antirretrovirais (ARVs) através do sistema único de saúde (SUS) por meio da Lei $n^{\circ}$ 9313/963. A terapia antirretroviral tem como principal objetivo fazer com que a imunodeficiência não progrida, restaurando à imunidade; diminuindo a morbi-mortalidade e melhorando a qualidade e a expectativa de vida ${ }^{4}$.

No Brasil, desde 2013 o ministério da saúde (MS) recomenda tratamento para todas as pessoas diagnosticadas com o vírus HIV, esta estratégia visa também bloqueio da cadeia de transmissão, visto que foram notificadas 100.000 novas infecções pelo HIV na América Latina em 20171 sendo 40 mil novos casos a cada ano nos últimos 5 anos no país ${ }^{2}$. Iniciar mais precocemente o ARV, além de impacto clínico favorável, vem demostrando importância na redução da transmissão do HIV, mas não pode deixar de considerar fatores como adesão e efeitos colaterais em longo prazo $^{5,6}$. O presente estudo tem por objetivo descrever e discutir o papel da medicação antirretroviral no cotidiano das pessoas vivendo com HIV.

\section{Materiais e Métodos}

Estudo qualitativo descritivo, realizado com pessoas vivendo com HIV com idade entre 18 e 70 anos, em uso de terapia antirretroviral, matriculados no ambulatório de um Hospital Universitário, localizado no município do Rio de janeiro. Os dados foram coletados por meio de entrevista gravada, utilizou- se dois instrumentos, sendo um questionário sócio demográfico e clínico, e um roteiro de entrevista, ambos elaborados após revisão de literatura. Coleta de dados realizada de julho a setembro de 2015, com aprovação no CEP da instituição (CAAE: 45955315.0.0000.5285).

Os dados sócio demográficos e clínicos foram tabulados, no programa Microsoft Excel ${ }^{\circledR}$ versão 2010. As entrevistas gravadas foram transcritas na íntegra e analisadas utizando a técnica de análise de conteúdo lexical, com o auxílio do software Iramuteq 0.7 alpha 2 (Interface de R pour les Analyses Multidimensionnelles de Textes et de Questionnaires). O Iramuteq realiza cinco tipos de análises, entre elas a classificação hierárquica descendente (CHD) na qual o estudo se deteve. Esta classificação permite uma análise lexical do material textual e oferece contextos (classes lexicais) e segmentos de texto mais característicos de cada classe permitindo sua contextualização, possibilitando a análise mais qualitativa dos dados com embasamento teórico adequado ${ }^{7}$. Os participantes foram identificados pela letra $\mathrm{P}$ seguida pelo número correspondente da entrevista.

\section{Resultados e Discussão}

\section{Composição da amostra}

A amostra foi composta por maioria do sexo masculino, solteiro, idade entre 30 e 49 anos e ensino fundamental incompleto. Situação clínica estável com níveis de $\mathrm{CD}^{+}$acima de 350 células e carga viral indetectável.

Pessoas do sexo masculino, solteiras, com idade entre 30 e 49 anos e poucos anos de estudo é o perfil de PVHIV encontrado nesta amostra e corroborado por alguns estudos ${ }^{8-10}$. Os últimos dados trazem que essa faixa etária vem caindo, demonstrando que a infecção pelo HIV está atingindo cada vez mais a população mais jovem ${ }^{2}$. O tratamento antirretroviral é eficaz na redução da carga viral. Assim o sucesso do tratamento é sinônimo de carga viral indetectável ${ }^{11}$. Para a PVHIV, o cuidado está ligado a tomar o remédio, o uso adequado fará a vida ser boa na opinião dos entrevistados. É possível perceber que a medicação tem um peso simbólico positivo nos relatos. Mesmo com a necessidade de medicalizar a vida este fato não interfere negativamente a percepção da qualidade de vida ${ }^{8}$.

\section{Análise computadorizada das entrevistas}

$\mathrm{Na}$ análise computadorizada dos dados das entrevistas obteve-se um dendograma composto por seis classes e dois eixos, neste material trabalhamos o primeiro eixo, que é composto pela classe 4 que representou $25,6 \%$ do total do material analisado, com 11 segmentos de texto caracterizando-a, sendo a classe mais expressiva. Esta, evidencia a importância que o tratamento medicamentoso tem na vida da PVHIV uma vez que convidados a falar sobre algo mais além das perguntas já realizadas, pontuaram a questão do remédio. As palavras mais relevantes nesta classe são: tomar e remédio expressando que neste momento o remédio é peça chave, um cuidado expresso pela medicação e pelo tratamento que fará com que tudo fique bem ao longo dos anos. A realização do tratamento através da tomada da medicação antirretroviral é vista como uma nova chance para a vida. Este colabora na redução da mortalidade, na diminuição das internações hospitalares 
e reduz a incidência de infecções oportunistas entre outros.

Abaixo os depoimentos que mais caracterizam esta classe:

Se ele se cuidar, se ele se tratar tomar o remédio, a perspectiva de vida dele vai ser boa, vai ser longa. (P43)

A aids não mata. Se vocêfizer o tratamento direitinho, tomar sua medicação direitinha, você vive por muitos e muitos anos (...). (P 31)

Mas o que acontece você fica muito bem sem o remédio por uma semana, na outra semana já começa a sentir falta no organismo, ai começa a dar febre, eu estava ficando em cima de uma cama. (P21)

Não desistir, tomar remédio, sim direitinho, enquanto há vida há esperança, eu estou vinte anos tomando remédio, já pensou se eu for largar abandonar, eu posso de repente chegar ao outro dia e morrer. (P27)

A gente acaba aprendendo que tem que se cuidar, e a não desistir da vida, conheço pessoas que está a trinta anos fazendo o tratamento e estão bem. Não pode desistir e nem desanimar. (P23)

Não me sinto sozinha, vivo bem, sou uma mulher forte, ah tem que ser a gente vai ficar triste, não adianta, tem que se cuidar procurar se cuidar, tomar os remédios certinhos. (P2)

A síndrome não é mais vista como letal a medicação e a adesão são peças chave uma vez que fica bem pontuada a necessidade de realizar o tratamento corretamente, demonstrando uma melhor compreensão da doença e também do tratamento proposto, a efetividade do tratamento perpassa pela adesão uma vez que o uso irregular e descontínuo da medicação acarreta outros problemas incluindo a resistência vira $^{14}$. Segundo o MS, adesão consiste na utilização dos ARVs da forma mais próxima possível da prescrita pela equipe de saúde, respeitando as doses, horários e outras indicações. É um processo colaborativo, onde o indivíduo necessita participar das decisões sobre seu tratamento o que pode facilitar a aceitação e a integração de determinado esquema terapêutico no dia-a-dia ${ }^{5,8}$. É um processo complexo que vai além da ingestão adequada dos antirretrovirais sendo necessário um fortalecimento emocional ${ }^{12}$ e para que isto ocorra, o diálogo deve ser franco e permanente entre PVHIV e profissionais de saúde a fim de se estabelecer não só um vínculo, mas a coparticipação do indivíduo. Visto que uma vez iniciada, a terapia antirretroviral deve ser continuada e problemas relativos à adesão como tomadas irregulares podem favorecer o aparecimento de resistência, dificultando o manejo da infecção ${ }^{3-4}$. Não se sentir efetivamente doente (com sinais e sintomas da síndrome) pode fazer com que a medicação seja descontinuada. Em cada visita à unidade de saúde, a pessoa, deve ser encorajada a relatar suas dificuldades e facilidades na tomada diária da medicação, bem como ser ouvida sobre suas motivações para a continuidade ou não do tratamento. Os indivíduos participantes do estudo percebem a eficácia dos antirretrovirais através de suas experiências e também as implicações decorrentes do desuso desta terapia.

A síndrome, ainda é cercada de estigma e preconceito, todavia, é percebida como uma doença crônica, que dispõe atualmente de inúmeras estratégias de tratamento e prevenção, sendo desmistificada e desvinculada da ideia de morte iminente. E, para as doenças crônicas o tratamento só é bem sucedido se o usuário tiver participação e envolvimento no processo sendo um sujeito ativo e corresponsável com seu plano terapêutico.A prescrição do profissional de saúde não terá nenhum peso ou contribuição se o sujeito não adotar um autocuidado com estilos e práticas de vida mais saudáveis e adesão ao tratamento e isto vai depender da consciência individual sobre suas condições de vida e a relação com sua condição de saúde. ${ }^{13}$ A inconstância, o abandono ou irregularidade do tratamento pode estar relacionado às falhas de compreensão ou mesmo ausência ou escassez de orientações sobre a terapia medicamentosa ${ }^{8}$ ou ainda caracterizar um comportamento de estratégia de enfrentamento chamada evitação onde o sujeito nega a doença não aderindo ao tratamento a fim de evitar confrontos com sentimentos dolorosos, mas este comportamento independente da motivação pode ter consequências danosas ao organismo ${ }^{12}$.

A importância da adesão à terapia medicamentosa com uso adequado do ARV para que a doença se mantenha controlada é reconhecido como fundamental pelas PVHIV e isto também é percebido como um fator de mudança na vida diária ${ }^{8,12}$. A adesão adequada ao tratamento e manutenção de uma vida social pode trazer como resultados uma melhora da qualidade de vida otimizando a mesma ${ }^{8}$. O cuidado disponibilizado para as PVHIV deve atingir diferentes aspectos orientação e apoio para que a importância da continuidade do tratamento seja percebida e que no cotidiano os desafios possam ser enfrentados com equilíbrio ${ }^{14}$.

A esperança pode significar um novo olhar sobre a síndrome para além das limitações da mesma percebendo a oportunização de novos caminhos principalmente pela medicalização. Esta parece demonstrar a presença de recursos internos suficientes para o emponderamento que ajuda na mudança, evidenciando que abandonar o tratamento pode mudar o curso da doença de vida longa e boa para a morte. Ela é reforçada, podendo ser observada através do otimismo, da não desistência, de se manter no caminho em busca de melhores condições de vida. E pode ser percebida como um sentimento que move o ser humano fazendo com que ele possa acreditar em resultados positivos propiciando mais qualidade de vida frente às dificuldades impostas pela doença e seu tratamento. 
E possivel observar a existência de uma consciência que o tratamento é longo e duradouro e que deve ser levado a sério para que a expectativa de vida se prolongue e com qualidade. Pessoas diagnosticadas no tempo oportuno e tratadas adequadamente podem ter a expectativa de vida comparável à de pessoas que não vivem com o vírus ${ }^{15}$. Em países desenvolvidos, PVHIV com contagem de células $\mathrm{CD}^{+}$acima de 350 células e carga viral indetectável tem a mesma expectativa de vida da população geral ${ }^{4}$.

A utilização do ARV repercutiu positivamente na saúde trazendo uma melhor perspectiva de vida principalmente na desconstrução da morte ligada ao HIV/Aids. O cotidiano vai sendo repensado e ressignificado ${ }^{10,16}$. Repensar crenças, ter apoio social e educação biopsicossocial sobre a síndrome pode levar a um melhor enfrentamento favorecendo a adesão ao tratamento ${ }^{12}$. Ter condições que proporcionem ao indivíduo acesso a moradia, alimentação, saúde e educação fortalecem a cidadania o que pode proporcionar uma visão mais ampla da importância do autocuidado na gestão da vida.

A medicalização da vida trouxe novas esperanças e o acesso ao tratamento deve ser entendido como um processo social e político e não apenas como a disponibilização de medicamentos ${ }^{17}$. Nesta ótica a consciência da necessidade da participação individual na gestão de seu plano terapêutico é bem evidenciada, e também uma consciência coletiva que o medicamento ajuda, entretanto a questão do HIV/Aids deve ser vista para mais além do que só o remédio. Os relatos trazidos mencionaram a questão da medicação antirretroviral como estratégia positiva de enfrentamento sendo referido a este o fato de ter uma vida boa desde que seguindo corretamente o tratamento.

\section{Considerações finais}

Avanços principalmente na terapia medicamentosa com novas formulações dos remédios, fazendo com que o número de comprimidos e de tomadas ao longo do dia pudessem ser otimizados são avanços que contribuíram para que a terapia antirretroviral se tornasse mais aprazível, os resultados mostram que os indivíduos entendem o tratamento como uma segunda chance para a vida, não é a cura, mas permite uma maior expectativa de vida e melhor qualidade de vida. E para tal precisam participar ativamente da gestão do seu autocuidado, aderindo a terapia medicamentosa. Acolhimento, escuta atenta, respeitosa, compreensiva, tolerante, esclarecedora e sem julgamentos morais por todos os profissionais envolvidos no cuidado a PVHIV, pode favorecer a criação de vínculos e melhor adesão ao tratamento, uma vez que uma conduta inapropriada pode influenciar diretamente no abandono do mesmo.

Os discursos revelaram sujeitos que compreendiam os benefícios do tratamento bem como os malefícios do abandono. Otımısmo e esperança de uma vida melhor frente à segunda chance que a medicalização oferece foi percebido no estudo.

\section{Referências}

1. UNAIDS. Joint United Nations Programme on HIV/AIDS. Knowledge is power - Know your status, know your viral load. 2019;92.

2. Brasil. Ministério da Saúde. Secretaria de Vigilância em Saúde Departamento de Vigilância Prevenção e Controle das Infecções Sexualmente. Boletim Epidemiológico - HIV Aids Julho de 2017 a junho de 2018. 2018.

3. Brasil. LEI No 9.313, DE 13 DE NOVEMBRO DE 1996. 1996.

4. Rachid M, Schechter M. Manual de HIV/Aids. 10a. Rio de Janeiro; 2017.

5. Brasil. Ministério da Saúde. Secretaria de Vigilância em Saúde. Departamento de Vigilância Prevenção e Controle das Infecções Sexualmente. Protocolo clínico e diretrizes terapêuticas para manejo da infecção pelo HIV em adultos. 2018.

6. Monteiro SS, Brigeiro M, Vilella WV, Mora C, Parker R. Desafios do tratamento como prevenção do HIV no Brasil: uma análise a partir da literatura sobre testagem. Ciência \& Saúde Coletiva. Maio de 2019;24(5):1793-807.

7. Camargo BV, Justo AM. IRAMUTEQ: Um software gratuito para análise de dados textuais. Temas em Psicologia. 2013;21(2):513-8.

8. De Andrade Moraes DC, De Oliveira RC, Arruda do Prado AV, Cabral JDR, Corrêa CA, Barbosa de Albuquerque MM. O conhecimento de pessoas vivendo com HIV/AIDS sobre a Terapia Antirretroviral. Enfermería Global. 30 de dezembro de 2017;17(1):96.

9. Medeiros B, Silva J da, SaldanhaAAW. Determinantes biopsicossociais que predizem qualidade de vida em pessoas que vivem com HIV/AIDS. Estudos de Psicologia (Natal). Dezembro de 2013;543-50.

10. Soares GB, Garbin CAS, Rovida TAS, Garbin AJÍ. Quality of life of people living with HIV/AIDS treated by the specialized service in VitoriaES, Brazil. Ciência \& Saúde Coletiva. Abril de 2015;20(4):1075-84.

11. Brasil. Ministério da Saúde. Secretaria de Vigilância em Saúde. Departamento de Vigilância Prevenção e Controle das Infecções Sexualmente transmissíveis do HIV/Aids e das hepatites virais. Cuidado integral às pessoas que vivem com HIV pela Atenção Básica Manual para a equipe multiprofissional. 2015.

12. Poletto, MP, Heck C, Calsa D da C, Moskovics JM. Pensamentos automáticos e crenças centrais associados ao HIV/AIDS em indivíduos soropositivos. Temas em Psicologia. 2015;23(2):243-53.

13. Brasil. Ministério da Saúde. Diretrizes para o cuidado das pessoas com doenças crônicas nas redes de atenção à saúde e nas linhas de cuidado prioritárias. 2013;(1a):30.

14. Tonnera LCJ, Meirelles BHS. Potencialidades e fragilidades da rede de cuidado da pessoa com HIV/Aids. Revista Brasileira de Enfermagem. Junho de 2015;68(3):438-44.

15. Brasil. Ministério da Saúde. Manual técnico de elaboração da cascata de cuidado contínuo do HIV. 2017.

16. Braga RM de O, Lima TP, Gomes AMT, Oliveira DC de, Spindola T, Marques SC. Representações sociais do HIV/AIDS para as pessoas que convivem com a síndrome [Social representations of HIV/AIDS for people living with the syndrome]. Revista Enfermagem UERJ [Internet]. 30 de abril de 2016 [citado 28 de janeiro de 2019];24(2). Disponível em: http://www.epublicacoes.uerj.br/index.php/enfermagemuerj/article/view/15123

17. Parker R. A reinvenção da prevenção no século XXI: o poder do passado para reinventar o futuro. 2016. 